\title{
Complex Traumatic Facial Degloving Injury
}

\section{Jadhav NC*, Sharad R, Lingam PP and Suhas S}

Department of Plastic and Reconstructive Surgery, Pondicherry Institute of Medical Sciences, Pondicherry, India

*Corresponding author: Jadhav NC, Department of Plastic and Reconstructive Surgery Pondicherry Institute of Medical Sciences, Pondicherry, India, E-mail: chandansurgery@gmail.com

Citation: Jadhav NC, Sharad R, Lingam PP, Suhas S (2014) Complex Traumatic Facial Degloving Injury. J Case Rep 2(5): 501. doi: 10.15744/2348-9820.2.201

Received Date: July 07, 2014 Accepted Date: July 15, 2014 Published Date: September 17, 2014

\begin{abstract}
By definition, degloving is detachment of skin and subcutaneous tissue, most often affecting the limbs and extremities and occasionally the scalp. Degloving generally occurs from high-energy trauma. This paper describes an extreme case of traumatic facial degloving injury. This is an extremely rare condition, as the patient survived despite the risk of imminent death. This case report addresses the decisions made regarding the emergency management, prevention of necrosis and infection by surgical debridement and timely repair of the vital soft tissue structures that guided the management.
\end{abstract}

Keywords: Facial degloving

\section{Introduction}

Degloving type of injury involves the separation of the skin and subcutaneous tissue from the bones, compromising the adjacent fascia, muscles, blood vessels and nerves [1]. Such injuries are more common in the limbs, but may occur in other parts of the body, such as the craniofacial region [2,3]. Owing to the rarity of patients who experience facial degloving there is no pre-established treatment protocol. The aims of initial treatment include maintaining the airway and control bleeding. A shorter operative time reduces the risk of infection and necrosis, thereby providing stable soft tissue cover for any subsequent procedures required for adequate function and aesthetics.

The authors describe a unique, extreme case of facial degloving involving the whole of the nose, lower eyelid, right cheek and upper lip; associated with comminuted fracture of nasal bones that required emergency measures for the stabilization and treatment.

\section{Case Report}

$35 \mathrm{yr}$ old male patient came with alleged history of road traffic accident. His main injury was to this face. He suffered full thickness facial laceration with degloving of whole of his nose, upper lip, right lower eyelid and right cheek. He also had comminuted fracture of his nasal bones with his nasal septum exposed and loss of his upper incisors (Figure 1). His CT brain was normal. On further examination it was noted that the degloved facial flap had another full thickness laceration on the left nasal ala. This whole flap was surviving despite the right facial vessels being avulsed.

The patient was intubated to secure the airway and underwent initial resuscitation. Under general anesthesia, wound margins were debrided till the edges were actively bleeding and was washed with normal saline. Nasal platform was first built by stabilising the fractured nasal bones with $22 \mathrm{G}$ stainless steel wires. Right infraorbital nerve was repaired with 8-0 nylon sutures. Deep anchorage sutures with prolene 3-0 were taken from the deeper surface of the degloved facial flap to the periosteum of zygoma and maxilla thereby reorienting the avulsed facial flap. Right medial canthal ligament was repaired. Upper lip was repaired in three layers. Nasal mucosal lining and upper gingivobuccal sulcus was sutured with 4-0 trugut. Finally the facial flap was sutured to the left side of the face in two layers. Nasal packs were placed to prevent collapse of the nasal lining and control nasal bleeding (Figure 2).

The whole of the facial flap survived including the dubious left nasal ala. Nasal packs were removed in $48 \mathrm{hrs}$ and facial sutures were removed on post-operative day 5. Patient was followed up at one and three month's period. He had near normal sensation over his avulsed face. He had normal nasal breathing and well settled facial scar (Figure 3,4). He had normal olfactory sensation. He initially had mild right sided epiphora which settled. He had enough upper gingivobuccal sulcus and was ready for dental rehabilitation. 


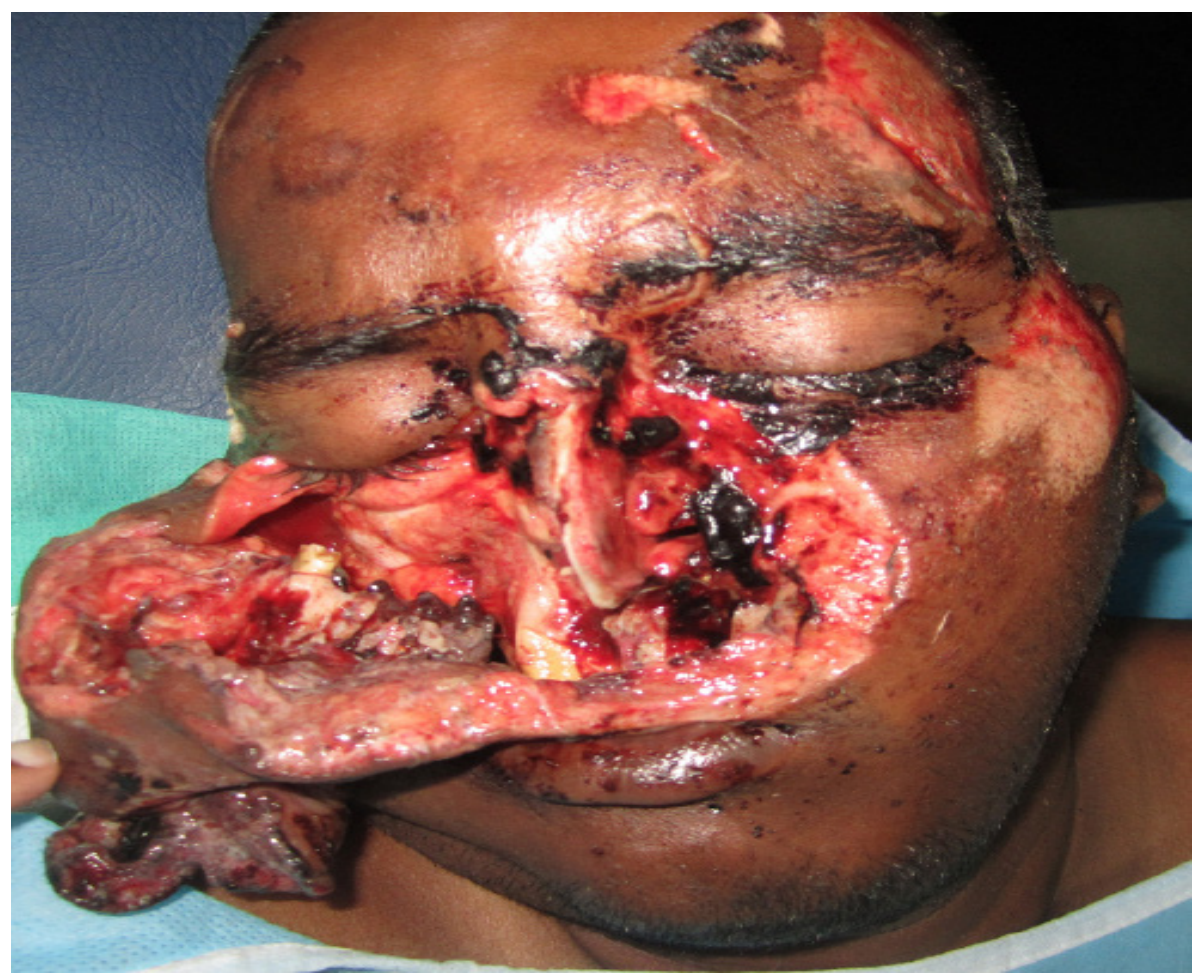

Figure 1: Degloved facial flap having the entire nose, right lower eyelid and upper lip. Exposed fractured nasal bones and nasal septum.

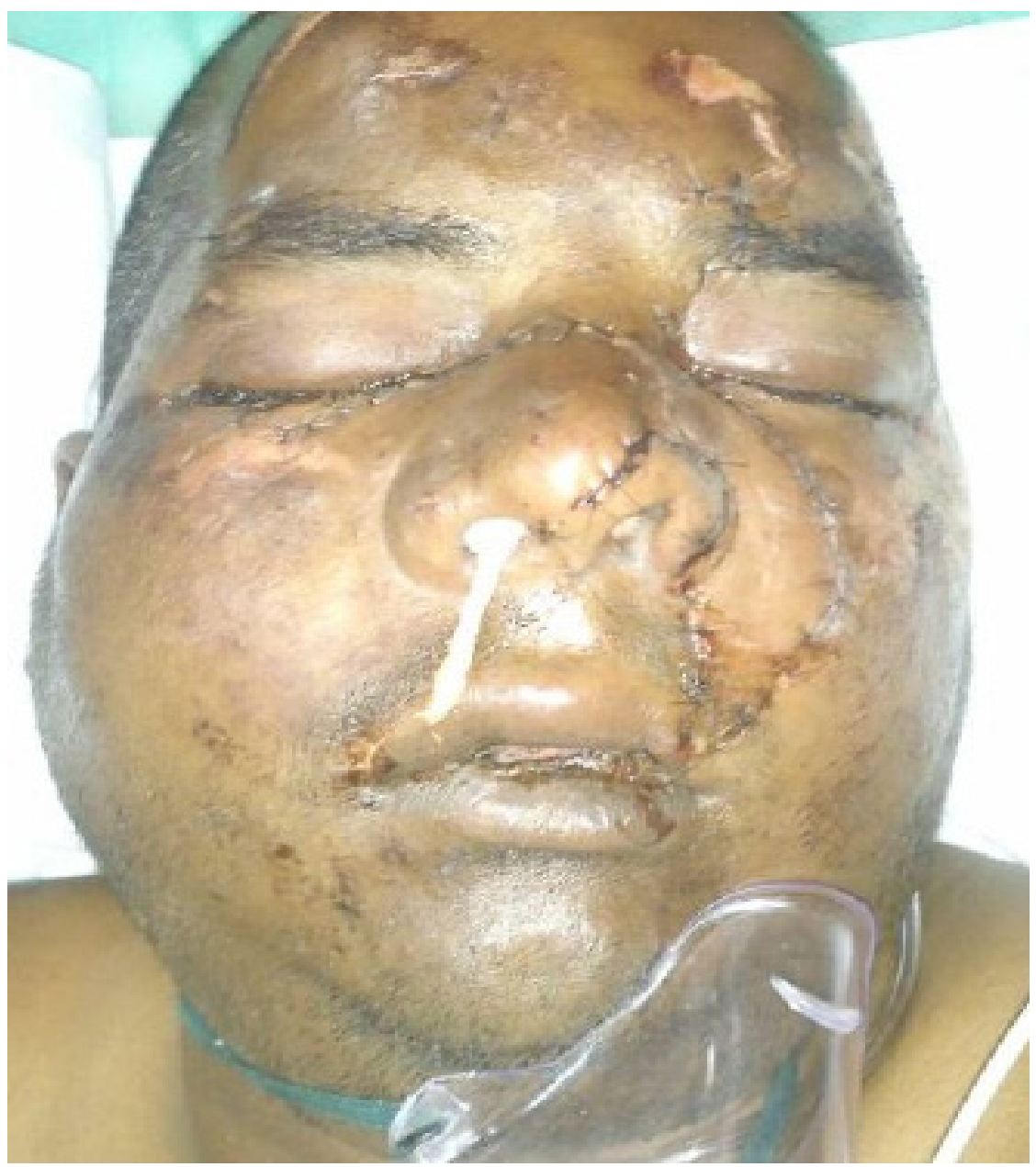

Figure 2: Immediate post-operative picture with sutured wound and nasal packing in situ. 


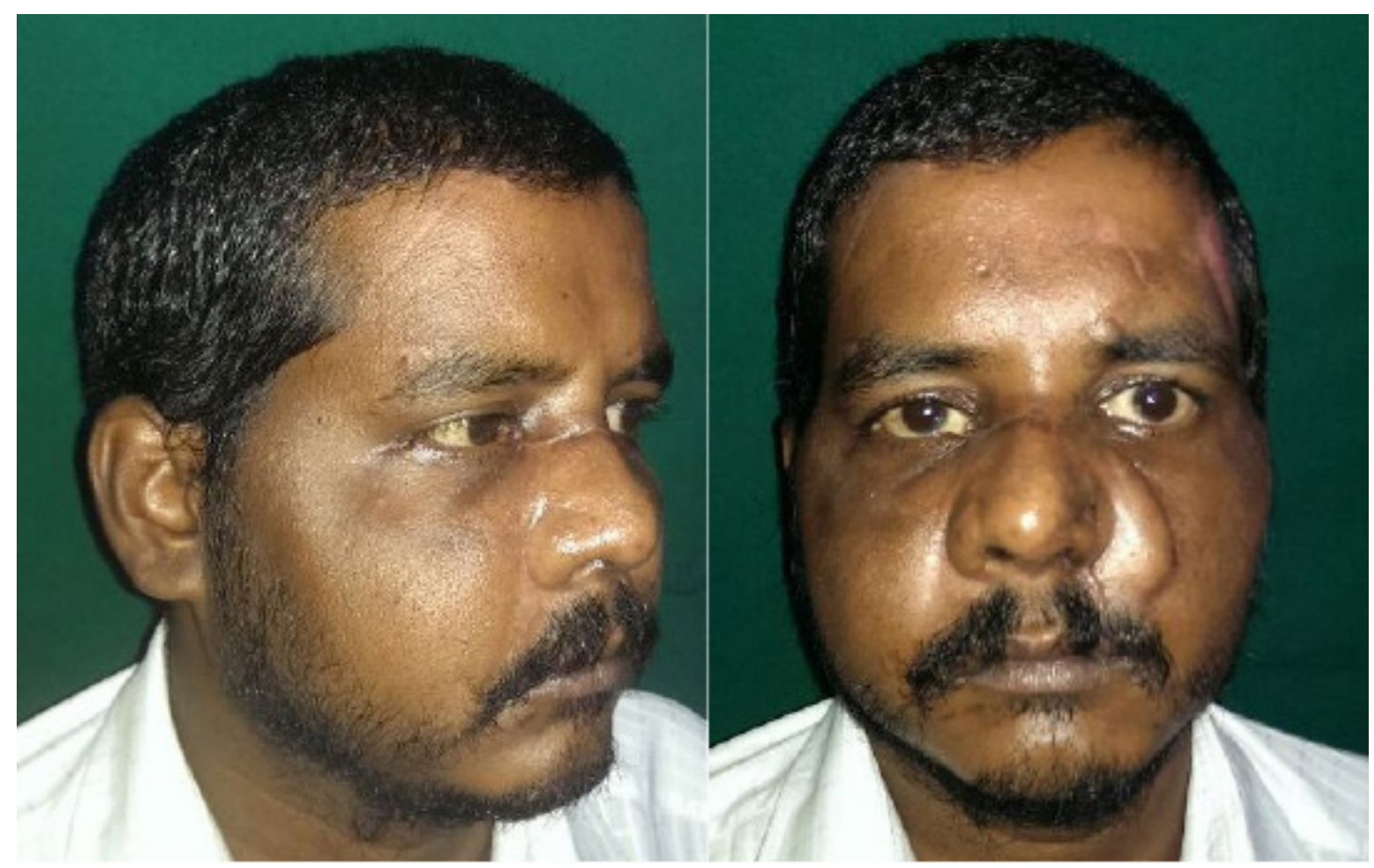

Figure 3: One month follow up with good nasal projection and function.

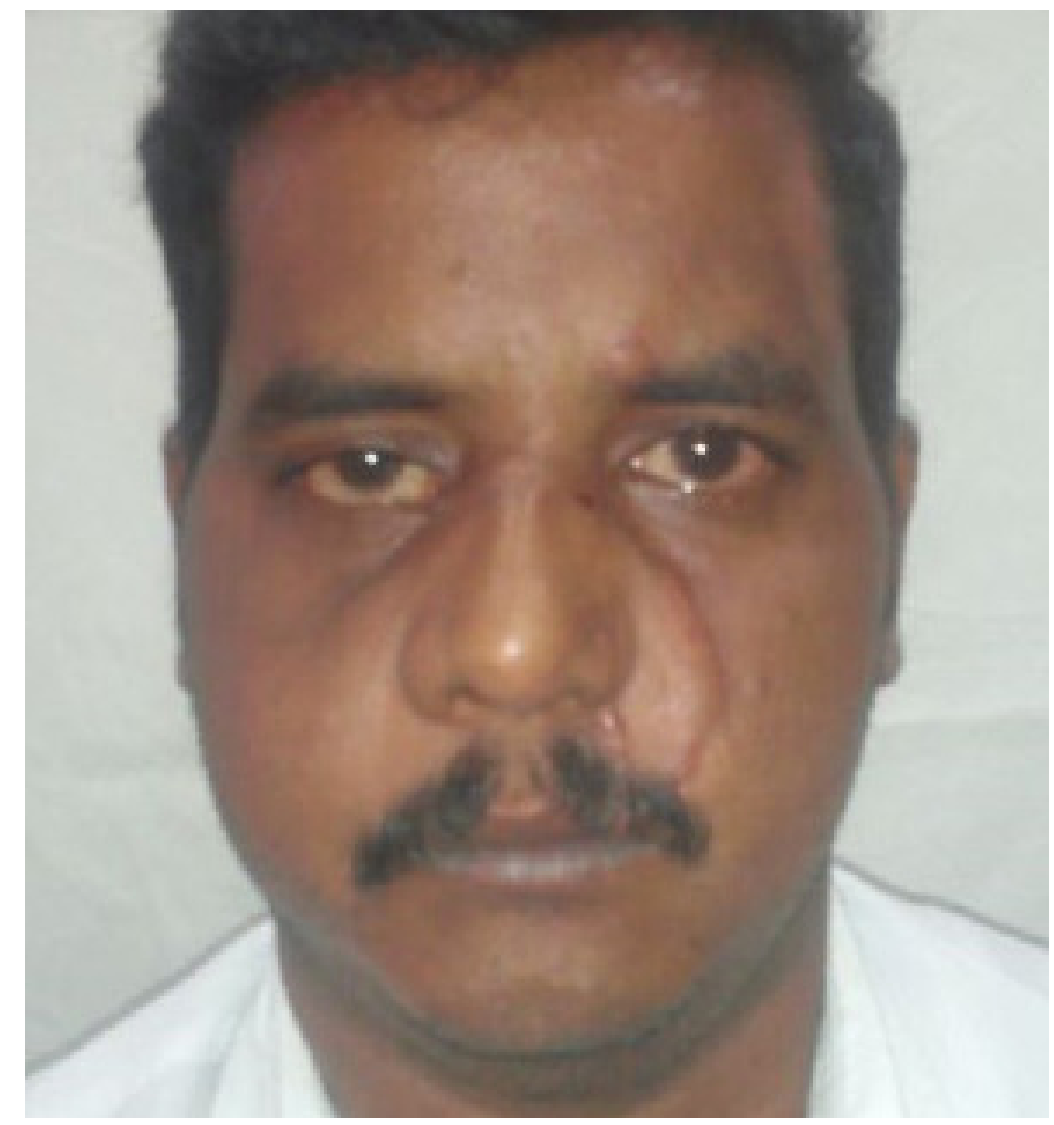

Figure 4: Three month follow up with well settled facial scar and near normal facial symmetry. 


\section{Discussion}

The aetiology of facial avulsion injuries is diverse; the most common are falls from trees, automobile accidents and accidents involving machines $[1,3,4]$. Most cases of avulsion caused by direct trauma are limited to small areas, such as the eyebrow, lip or ear. Indirect trauma, such as catching hair in machines, tends to cause larger injuries [4]. Avulsion injuries of the face are uncommon, whereas avulsion of scalp tissue, with or without facial tissue, are reported more frequently [5]. Avulsion injuries involving the complete degloving of the affected segment require immediate treatment and generally involve the use of hyperbaric oxygenation and microsurgical techniques to reduce tissue necrosis $[2,6,7]$. The case presented here differs from cases in the literature, both in the extent of the affected area and the possibility of successful repair without the use of hyperbaric oxygenation or microsurgical techniques. The team decided on this approach because there were no vessels available and viable for anastomoses. Even stopping the flow of blood from facial arteries did not represent a concern as the ligature of this artery is a routine procedure in oral and maxillofacial surgery, especially when accessing the lower face.

Nasal fractures were stabilised quickly with $22 \mathrm{G}$ stainless steel wires, building the platform for the soft tissues to rest. In most patients early reduction and fixation of fractures, along with correction of the traumatic telecanthus during the initial surgery, yields the best results [8]. The injuries presented by patients can affect several special anatomical structures, mainly in the periorbital area. Injuries to the eyelids, medial canthal ligaments and lacrimal apparatus increase the complexity of surgery and make the results less predictable. Frequent complications associated with these structures are increasing intercantal distance, epiphora, and incorrect positioning of the eyelids. The ideal period for treatment of periorbital injuries is during the acute stage. Two weeks after trauma, treatment becomes less predictable and more subject to relapse, especially the intercantal distance. The secondary corrections are more complex and produce less satisfactory results than primary treatment [8].

\section{Conclusion}

A well-directed approach with stabilization of the airways and control of bleeding is of fundamental importance in cases of avulsion. The use of microsurgical techniques for the reestablishment of lost vascularization should be considered, especially in cases of complete tissue avulsion. Partial degloving of the face may not require such anastomoses, possibly due to the rich facial vascularisation and collateral circulation, as in the present patient.

\section{Acknowledgement}

I thank the on call junior resident Dr Sundar Rajan and the theatre staff whose immense contribution was noteworthy.

\section{References}

1. Olateju OS, Oginni FO, Fatusi OA, Faponle F, Akinpelu O (2007) Multiple midface degloving injury in an elderly man: challenges and management outcome. J Natl Med Assoc 99: 810-3.

2. Khandelwal S, Wall J, Kaide C, Katz G (2008) Case report: successful use of hyperbaric oxygen therapy for a complete scalp degloving injury. Undersea Hyperb Med 35: 441-5.

3. Liu T, Dong J, Wang J, Yang J (2009) Microsurgical replantation for child total scalp avulsion. J Craniofac Surg 20: 81-4.

4. Uda H, Tachi K, Suga H, Sugawara Y(2006) A clinical case of facial avulsion injury with huge bone defect. J Trauma 61: 1526-31.

5. Bergmann J, Lee K, Klein R, Slonim CB (2009) Upper face and orbit "degloving" dog bite injury. Ophthal Plast Reconstr Surg 25: 44-6.

6. McMullin BT, Rhee JS, Pintar FA, Szabo A, Yoganandan N (2009) Facial fractures in motor vehicle collisions: Epidemiological trends and risk factors. Arch Facial Plast Surg 11: 165-70.

7. Singh J, Doddridge M, Broughton A, Goss A (2008) Reconstruction of post-orthognathic aseptic necrosis of the maxilla. Br J Oral Maxillofac Surg 46: 408-10.

8. Herford AS, Ying T, Brown B (2005) Outcomes of severely comminuted (type III) nasoorbitoethmoid fractures. J Oral Maxillofac Surg 63: $1266-77$.

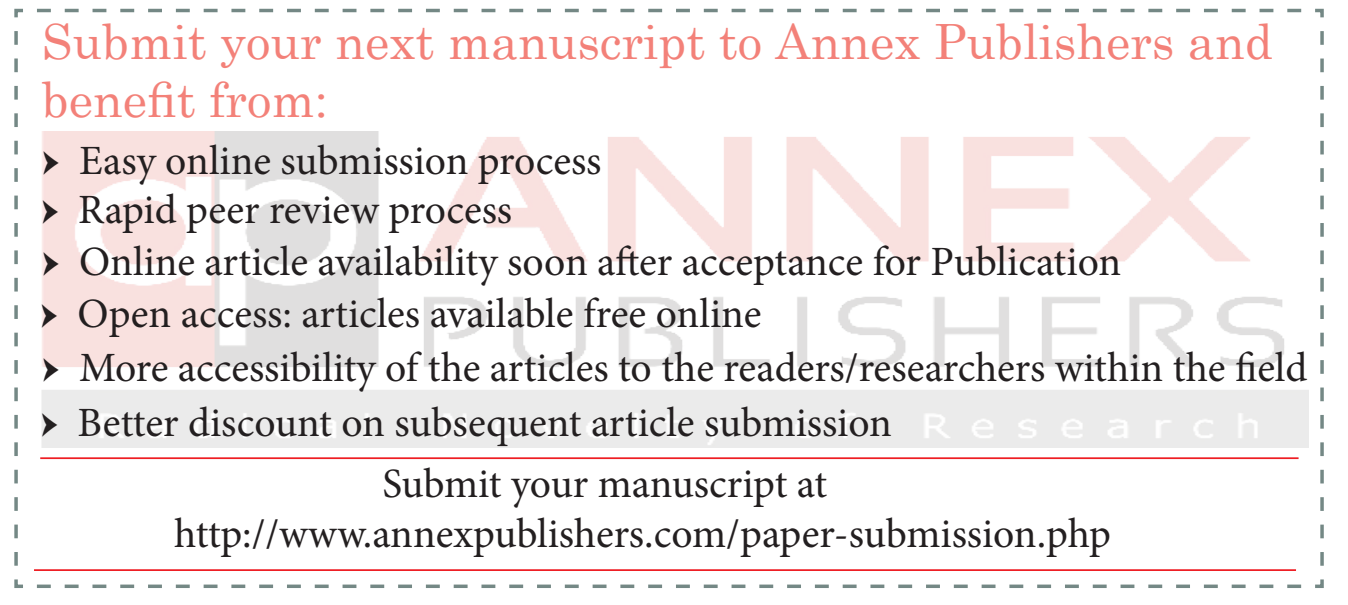

